\title{
(Re)thinking Lived Curriculum as Complicated Conversation through Nomadic Thought in Pursuit of Curriculum Transformation
}

\section{Shan Simmonds \\ ORCID iD: https://orcid.org/0000-0001-5005-9906}

\begin{abstract}
The discontent regarding the dismantling and critiquing of the dominant inscriptions of curriculum by South Africa's higher education institutions continues to be experienced. Over twenty years into its democracy, curriculum transformation is yet to be realized and one reason for this is the proliferation of policy frameworks that have, for the most part, reinforced technobureaucratic compliance with structural change and framed myopic conceptions of curriculum. In an attempt to engender a curriculum discourse that shifts the focus from policy to the centrality of the subject, in this article I engage with subjectivity and the lived curriculum in what Ted Aoki thinks of as a constructive tensionality. This tensionality lies in the transcendental conception of the subject that very often succumbs to imperatives of myopic elements of such curriculum discourse. From the main findings of a research study that drew on the lived experience of students who invested in complicated conversations, their aspirations for curriculum transformation became evident. This initiated a much needed (re)thinking of lived curriculum as complicated conversation and what this could entail in a posthuman era. The desire for complicated conversations to enable curriculum transformation requires a shift in hegemonic conceptions of the subject and of knowledge. I embrace these possibilities through nomadic thought.
\end{abstract}

Keywords: lived curriculum; complicated conversation; nomadic thought; curriculum transformation, posthumanism 


\section{Higher Education and Curriculum Transformation}

For many years, curriculum was most vividly discoursed within schooling and less so in higher education (Barnett \& Coate 2005; Le Grange 2006). Besides the standardization of school curriculum, its socio-political agendas also attest to the need for continual curriculum reform and debate in this sector. Although higher education is equally politicised, dismantling and challenging curriculum featured less here. Le Grange (2019a) refers to the neglect of matters curricular in higher education as a result of pressures exerted by the state both nationally and internationally in prioritising massification, neoliberalism, globalisation, and internationalisation.

The neglect of matters curricular was also driven largely by a proliferation of policies spanning most of the first two decades post-1994. These policies were geared predominantly towards structural and ideological transformation of higher education (Du Preez et al. 2016; Soudien 2010a). Lange (2017) describes higher education reform in the first decade after 1994 as having been dominated by policy development and implementation closely in line with the 1997 White Paper's structural objectives (Department of Education 1997). The focus was on addressing and reconciling inequalities in governance, funding, and quality assurance through heightened policy measures that strived for redress, equity, efficiency, access, and success. Preoccupied with structural institutional compliance, the discourse started to change in the second decade (around 2008) through the appearance of a dominant ideological policy discourse. Sparked by South Africa's still divided racist and sexist society (Soudien 2010a), a historic event at the University of the Free State (Reitz-saga) in 2007 led to one of the tipping points for the necessary but long-overdue engagements with broader conceptions of transformation that encompassed the cultural and social university environment (see Soudien 2010b) for detailed explanations of what this event entailed). A subsequent report of the Ministerial Committee into Transformation in Higher Education (MCTHE) (Department of Education 2008) lay the ground for epistemological change, inclusivity, and diversity in all its facets (Du Preez et al. 2016). Lange (2017:33) sums up well these two decades of higher education in light of curriculum transformation. The structural transformation period of the first decade "was more interested in the exoskeleton of the curriculum, that is, the structure and purpose of qualifications as presented in the National Qualifications Framework (NQF)'. 


\section{Shan Simmonds}

As a result, policy choices succumbed to national economic and development goals and 'did not create the space for any investigation of knowledge and pedagogy in the curriculum' (Lange 2017: 34). While the policy discourse of the second decade explicitly raised the importance of curriculum transformation, " 'no serious engagement at intuitional level with knowledge as epistemology, with knowledge with different frames of understanding, and with knowledge as creator of identity' were embraced (Lange 2017: 34).

In 2016, the Council on Higher Education publicised a report wherein higher education was reviewed two decades after the establishment of democracy. The task team on teaching and learning further expressed these somber realities when they highlighted that although strides had been made in the 'structural domains' of higher education curriculum through policy related improvements, 'it has made very little progress in the arguably more important 'cultural domain' of ideas and theories' (Council on Higher Education 2016: 171). This came at the cost of cultivating moral persons and infringed on the optimal possibilities for curriculum to be a deliberative encounter, one of openness, mutual respect and critical engagement with different epistemologies and subjectivities. This reinforces the complexities of curriculum transformation and the need to reject reductionist, essentialist, and one-dimensional conceptions thereof.

For Lange (2017), a more nuanced outlook on curriculum is needed. She presents her arguments within the \#Fallism movements occupying higher education institutions since October 2015. She opines that students' outcries for curriculum transformation are heavily, but not only, entrenched within the need to challenge Western, phallocentric, dominant content in the curriculum. Alongside this disciplinary knowledge, institutional knowledge cannot be ignored. Institutional knowledge is tattooed into the social fabric of the university since it underpins tactic assumptions about knowledge, its practices, and lived experiences. As a social epistemological moment in the wider student movement, curriculum transformation cannot be simplified; it must involve institutional culture since it affects its terms of purpose and content directly and raises questions about academic authority, the meaning of democracy, and equity. Contrary to what was possible in the first two decades post-1994, Lange

${ }^{1}$ The MCTHE report (South Africa, 2008) is a prominent example since it bluntly exposes the fossilised institutional cultures and unchanged curriculum as being direct obstacles to the transformation of higher education. 
proffers that this level of curriculum transformation cannot be realized through any form of policy framework, old or new. The university needs to step up to the plate if it wants to confront and address the deep-seated curriculum questions inhibiting transformation. This does not imply that the responsibly lies only with top management; there is urgency at the grassroots level for academics and students. Lange cautions that this should be engendered as a process since it entails bold self-examination, the dismantling of power, and the stimulation of dialogue and debate among all role players. This will be the ultimate test for South Africa's universities that have chosen to remain myopic in terms of curriculum transformation since 1994.

Given its centrality, the higher education curriculum remains the cornerstone of efforts to (re)think transformation. However, such transformation would be possible only through an expanded notion of curriculum. Le Grange (2019a: 41f) suggests that this requires curriculum to be more than its planned activities and policy frameworks in that it needs to give 'legitimacy to students' lived experiences and to experiment with new ways of doing that to open pathways for students to become, instead of colonizing students' desires and potential to create newness in the world, through privileging a predetermined curriculum'. This creates, in part, what Aoki (1993: 257) alludes to as a 'tensionality', the constructive/ destructive contentions that can emerge through the in-dwelling of curricula as prescribed and as lived. I begin this article by attempting to engage in the constructive tensionalities of subjectivity and curriculum as lived. I explore the subject as ecological for its immanent potential. Thereafter, I give legitimacy to particular students' experiences of, and aspirations about curriculum transformation through their explicit non-participation in the student protests that have marked the landscape since 2015. Their experiences of the curriculum, although specifically surfaced by the ongoing student protest that began in 2015, indicate how students view curriculum transformation and the forces influencing this. One of their key aspirations is for curriculum transformation to be fostered through complicated conversation rather than protest. We need to contemplate what such complicated conversations might entail for a lived curriculum in the world of the posthuman condition in which hegemonic, unitary, and predetermined subjectivities can be challenged. I conclude this article by considering what such complicated conversations might entail if they are to open up alternative pathways to pursue curriculum transformation so that the curriculum as lived is an act of creation rather than of reproduction. 


\section{Subjectivity and the Lived Curriculum: A Constructive Tensionality}

Being mindful of students' experiences resonates in the language of a lived curriculum which offers 'the more poetic, phenomenological and hermeneutic discourse in which life is embodied in the very stories and languages people speak and live' (Aoki 1993: 261). It challenges a curriculum topography fundamentally informed by 'the lure of Western epistemology' that dictates 'our beliefs about knowing and knowledge, [and] which has given our universities and schools a striated curricular landscape' (Aoki 1993: 256). We have become so deeply infected by Western curricular landscapes that our preoccupation with structure and compliance has meant that we have failed to engage with the much-needed questioning of curriculum. Curriculum, 'in spite of its inherent indefiniteness, has become definitive, so much so that we speak with ease of the curriculum'. Privileging a single curriculum, in its arboreal sense, echoes the 'chiseled motif of the striated linear instrumentalism deeply inscribed into our [curriculum] landscape' (Aoki 1993: 259). For Aoki this evokes the 'crisis of modernity in the Western world, a questioning of the way of life we have constituted as modernism'. We need to 'reunderstand our curricular landscape' by 'disturbing the landscape' that holds faith in critical reason to apprehend and transform society (Aoki 1993: 257). To disturb or trouble emphasises the urgency of challenging deeply inscribed conceptions of curriculum such as the traditional curriculum studies discourses that deny subjectivity. Through the reconceptualization of curriculum studies, curriculum resonates as currere (Pinar 1975). This includes the politics of presence, space/place, and the ethical dealing with alterity or, in other words, otherness or the state of being other or different. Currere provides an autobiographical method for studying the self so that both individuals and groups can understand teaching as passionate participation in the complicated conversation that is the curriculum. Pinar's (2012) curriculum theory emphasises the significance of subjectivity to education.

The curricular challenge is thus simultaneously subjective and social as it 'seeks to understand the contribution academic studies make to one's understanding of one's life (and vice versa), and how both are imbricated in society, politics and culture' (Pinar 2012: 45). The curriculum requires 'subjectivity in order for it to speak, for it to become concrete, to become actual. Without the agency of subjectivity education evaporates, replaced by 
the conformity compelled by scripted curricula' (Pinar 2012: 43). This agency, Pinar argues here, is dependent on the cultivation of subjectivity as situated and historically attuned.

For Braidotti (2011: 18) subjectivity involves 'a socially mediated process of entitlements to and negotiations with power'. Central to her conception of nomadic subjectivity is a dissatisfaction with our advanced capitalist world with its dominating phallocentric schemes of thought that create 'hegemonic, fixed, unitary and exclusionary views of subjectivity' (Braidotti 2011: 58). Instead a non-phallocentric way of thinking, informed by feminist theory, attracts her since it stresses the limitations of logocentric approaches and shifts the emphasis to other ways and modes of representation both human and non-human. The desire is to leave behind linear modes of thinking ordained in teleological argumentation and to 'start cultivating the art of disloyalty, or rather, ... the healthy disrespect' that is needed to imagine affirmative representations of an embodied subject (Braidotti 2011: 24). Nomadism is about critical relocation, about becoming situated through embodied and embedded materialism so as to transform our knowledge of ourselves and of the world. Within this notion is a heightened desire for becoming-other, the affirmative activity that is relational, ethical, and situated. This requires identifying lines of flight for 'creative alternative spaces of becoming' from within (Braidotti 2011: 7). Continuous becomings from within accentuate subjectivity as multifunctional and complex, 'as a transformer of flows of energies, effects, desires and imaginings' so that it does not get subsumed in dichotomous renderings of Cartesian dualities (Braidotti 2011: 17).

In light of what this could mean for curriculum as currere, Le Grange (2019b) emphasises that conceptions of currere such as those of Aoki (1993) and Pinar (2012), reinscribe a transcendental view of the subject invested in strong phenomenological foundations. The subject is prized as an a priori image of a pedagogical life that privileges the individual (and their reflection of self and other) in such a way that it gives fixity and closeness to curriculum thinking. Wallin (2010) reimagines currere from its first intended meaning ('the course to run') as Pinar (1975) reminds us, to contemplate instead what currere wills to power so as to unlock what it does or might do. Wallin's focus is on 'root[ing] out a legacy of transcendent thinking in curriculum studies that continues to reduce potentials for thinking new forms of subjective and social organisation ... [and that gives] rise to the proliferation of institutional nihilism, 


\section{Shan Simmonds}

cynicism, and conservatism' (Wallin 2010: $\mathrm{x}$ ). This has led to the reactive conceptual force of Western university education in the twentieth century where 'one way of doing has become the way of doing', and this has further led to,

instrumentalist approaches to teaching whereby outcomes or aims are predetermined and often derived from existing disciplines. Students are tracked by standardized tests and kept on track by subject disciplines. The territorialization of currere's active force has led to the ossification of potential movements, thwarting of experimenttation, freezing of living and domestication of self (Le Grange 2019b: 215).

An active conceptual force of currere is more invigorating since it allows for the liberation of the subject 'who is no longer cathected to pre-existent identity structures' (Wallin 2010: $\mathrm{x}$ ) and to the creation of 'new types of decentered subjects and social organisations [so that] curriculum is approached as an act of creation rather than reproduction' (p. xii). For Le Grange (2019b: 221) this enables multiple coursings for the becoming of a pedagogical life, with immanent potential, so that subjectivity is not individual but ecological, a 'humble "I"' that is 'embedded, embodied, extended and enacted'. The concept of ubuntu-currere, coined by Le Grange (2019b), encompasses these ideas. Driven by the possibilities invested in an active conceptual force of currere (as the positive power of potentia that connects, expresses desire and sustains life), ubuntu-curerre 'shifts our registers of reference away from the individual human being to an assemblage of human-human-nature [so that] subjectivity is ecological' (Le Grange 2019b: 222). What this means is that it is not only the oneness of self with other humans, but also the 'oneness of self and the cosmos [that] provides the impetus for becomings that are caring towards other humans and the more-than-human world' so that education fosters cooperation and not competition (p. 222). This image of education embraces the desire to live, to connect, and to care for other humans and the more-thanhuman-world by opening up multiple coursings for the becoming of a pedagogical life. The subject is then always in-becoming and driven by an affirmative ethic that 'actively strives to create collectively empowering alternatives [as] transformative and inspirational ... [and by] an active commitment to the social horizons of hope' (Braidotti 2011: 14). 
Contemplating the musings of subjectivity creates the necessary constructive tensionalities needed for opening up alternative pathways for (re)thinking curriculum as lived. This is especially necessary given the complex challenges we face in our world, one that involves, and revolves around, the self, social relations, technological advancements, and the environment. The curriculum as lived, informed by nomadic subjectivity and ubuntu-currere, challenges us to think differently about the human gaze etched in what is the living, to live and the lived in what we know as the curriculum. A subject fully immersed in processes of becoming, offers an active conceptual force of currere (Le Grange 2019b) so that 'power, knowledge and desire [are] a positive vision of the subject as affective, productive and dynamic' (Braidotti 2011: 17). As a subject of becomings, the lived curriculum decenters ' $[\mathrm{m}] \mathrm{an}$, the former measure of all things' so that it can proffer a 'nature-culture continuum' (Braidotti 2013: 2). However, such a continuum is not possible when education informed by humanism is driven by potestas (currere's reactive conceptual force) since it could centralise control, colonise desire, and predetermine 'the course to run through predefined aims, objectives or outcomes ... [thus] territorializing currure's active force into a reactive force' (Le Grange, 2019b: 221). For Braidotti (2013) potestas resonates within the binary opposition between the given and the constructed as perpetuated by social constructivist approaches that have too long enjoyed widespread consensus. The danger is that 'social constructivist methods sustain the efforts to de-naturalize social difference and thus show their man-made and historically contingent structure' (Braidotti 2013: 3). Her posthuman subjectivity must be premised, rather, on the vital, self-organising and yet nonnaturalistic force of living matter itself, through a non-dualistic understating of nature-culture interaction. In our ever-changing landscape of scientific and technological advances, the boundaries between the natural and the cultural need to be 'displaced and to a large extent blurred' (Braidotti 2013: 3).

The principle of non-linearity can help us to imagine subject formations as they might evolve in a nature-culture continuum. The in-between or within (as promoted by a continuum) cannot be linear and process oriented. Instead, it 'strikes a new deal in actualizing the practice of conceptual personae or figuration as the active pursuit of affirmative alternatives to the dominant vision of the subject' (Braidotti 2013: 164). A lived curriculum that is nonlinear accounts for the complexity of our contemporary world; it recognises that 'the heteroglossia of data we are confronted with demands complex 


\section{Shan Simmonds}

topologies of knowledge for a subject structured by multi-directional rationality' (Braidotti 2013: 164-165). In a continuum, time needs to be embraced as Aion (the dynamic and more cyclical time of becoming that is curiosity-driven) and not Chronos (dominant time that is protocol-bound) (Braidotti 2013: 165). The principle of non-linearity thus enables us to unlock Aion as different temporality and a creation of new things through curiosity so as to critique the powers that dominant linear concepts hold for the subject. Here the subject as embodied, embedded, and embrained can affectively open out towards geo-philosophical and planetary dimensions through 'the threshold of gratuitous (principle of non-profit), aimless (principle of mobility or flow) acts which express the vital energy of transformative becoming (principle of non-linearity)' (Braidotti 2013: 166-167).

Subjectivity needs to be attuned to the posthuman condition, needs to embrace a nature-culture continuum of non-linearity, and needs to be embodied, embedded, and embrained. When curriculum as lived takes accountability for these constructive tentionalities as an affirmative ethics based on collaborate morality, alternative pathways in pursuit of curriculum transformation can emerge.

I go on, in this article, to give legitimacy to students' lived experience in an attempt to understand how they experience the curriculum and the underlying agendas that they regard as influential for curriculum transformation. The intention is not to attribute their experiences as the (humanistic) way of understanding the (linear) curriculum, but, rather, as $a$ perspective depicting curriculum transformation. Taking heed of these lived experiences as a departure point means recognising $a$ view of the agendas (the students') and implicating curriculum transformation in the consideration of alternative pathways for lived curriculum as complicated conversation.

\section{Research Process}

I elicited the experiences of students enrolled in a postgraduate curriculum studies programme at my institution between 2015 and 2019. Students were invited to voluntarily participate in a once-off interview during which they could share their experiences and opinions of the student movements that occupied higher education in the name of transformation. Since they are Bed. Hons students specialising in curriculum studies, their voice was deemed significant since it depicted their current lived experiences, expressed their 
hopes in this historical movement, and disclosed what they thought about curriculum transformation. A total of 14 students participated. This number of participants represents the size of this programme where enrollments of between two and ten are common. In fact, from 2015 to 2017 there were only, on average, three students per annum with curriculum studies as their major and this increased only slightly in 2018 and 2019. The participants were diverse in relation to gender, ethnicity, and socio-economic background and there were both full-time and part-time students. The five full-time students were continuing their studies and came directly from B.Ed. or PGCE programmes. Of the nine part-time students, three were teaching at high schools and the other six at primary schools. The schools were situated in urban and rural areas in the provinces of Gauteng and North West. Their subject areas included Setwsana Home Language, English First Additional Language, Social Sciences, Life Orientation, Economic Management Sciences, Mathematics, Natural Science, Technology, and overall Foundation Phase subjects (numeracy, literacy and life skills). Each participant chose a pseudonym to be used when their responses were documented to protect their identity.

In the interviews, students were asked to share their involvement or non-involvement in the student protests movements and to reflect critically on this. This included being explicit about how the protests unfolded, what roles they played, and what they regarded as key agendas influencing curriculum transformation in higher education. These topics speak to the curriculum as lived (Aoki 1993; Pinar 2012) since their exposition relies heavily on the experiences of students whose social fiber is intricately interwoven into all aspects of the university (Lange 2017) and not just on the experiences of students seen as the clients of the neoliberal university that produces graduates for an economic workforce. Of course, what students experience matters and must be seen to be central to agendas that influence curriculum transformation in higher education.

\section{Legitimizing Students' Experiences}

From the engagements with the student participants, it was clear that not one of them participated in the student protests. Of significance to this article are the reasons behind their non-involvement. They revealed explicit and implicit agendas that are inhibiting curriculum transformation and their experiences of these gave rise to their discontent with curriculum transformation in higher 


\section{Shan Simmonds}

education. They disclosed their thoughts on how students could be involved in curriculum transformation in the future or in future times of student uprising. Five themes capture what the student participants experienced as the underlying agendas influencing curriculum transformation. The first four themes, all of which disclose reasons for the lack of transformation, are: curriculum as a political act; curriculum as a social product; the reactive force of curriculum; and economic repercussions and curriculum transformation. The fifth theme, allegorical approaches for curriculum transformation disclose the aspirations of students to foster complicated conversations as an alternative to protest actions.

\subsection{Curriculum as a Political Act}

Three participants referred explicitly to the protests as a political act that is part of an agenda that inhibits curriculum transformation. For Lucia, South Africa's political climate is violent and hegemonically driven. She explained,

I think the problem is with our government. The South African people are used to demanding things with violence because if they speak ... they're only heard through violence that's how this government is operating. My view with that is that is how the leadership of the country regain[s] the power, by creating this culture that in order for you to be heard as citizens, you vandalise, and you fight. Then they come back and solve the problem that they created.

This speaks to Lesedi's conjecture that the protests were an agenda of politicians 'to gain political power' because 'most people who were leading the protests were not registered students in tertiary institutions'. They were politicians. So, whether students protest or not, Othandwayo believes that 'the government does what is in their political power without hearing from the mass. So, they will do what they want to anyway'.

For these students, the protest movements were politicized. In having a political agenda, curriculum transformation could be regarded as an act of political symbolism and a means for government to legitimate itself (Jansen 2002). Cross et al. (2002: 186) argue that "very often in educational reforms political concerns are made to prevail over educational and pedagogical concerns in order to mediate conflicting interests in the political domain'. 
Curriculum transformation becomes a political statement that reflects students' struggles as the opposing group, or the oppressed (Chisholm 2005). This reinforces the belief that curriculum transformation is influenced directly by the political sphere and that the curriculum is political.

\subsection{Curriculum as a Social Product}

Lindie's and Elana's responses questioned the ability of the protest movements to unite students when they articulated the tendency for these movements to be exclusionary and discriminatory. Lindie longed for unity and the common cause. Instead, she experienced that students 'did not serve a common cause, and [the protests] appeared to draw more racial lines and barriers between black and white people'. For Elana, it becomes counter-productive if 'decolonialisation and transformation are being used to promote divisions in the country rather than counter [them]'. These student participants experienced the student protests in the name of curriculum transformation as creating a divide rather than uniting students. For Chisholm (2005) when curriculum is a social product curriculum will be a complex and turbulent process because it includes contestations between multiple social forces and actors and cannot be the product of any one such social group. Desires of social groups are negotiated on various levels. On the one hand, this could include taking into consideration the direct interests of social groups or, on the other hand, acknowledging instead how these interests come forth through other social forces or are even mediated by broader goals and visions of underpinning the curriculum (Chisholm 2005).

Furthermore, curriculum as a social product becomes further complicated from within and between the social forces it encounters and engenders. This could be because curriculum is so deeply inscribed in situated knowledges (Haraway 2006) and knowledge in the blood (Jansen 2009) that although students are advocating for curriculum transformation (perceived as a 'common cause'), this can never be uniform and uncomplicated because the student body itself is diverse and further complicated by actors such as the institutional curriculum. This resonates with Jansen's (2017: 162) conception of entangled knowledge which recognizes that our knowledge is 'intertwined in the course of daily living, learning and loving' so much so that 'we cannot escape our entangled lives, which are inevitably reflected in what we know and how we know it'. 


\subsection{The Reactive Force of Curriculum}

The violent nature of the protests was raised by six of the student participants and this signaled concern for enabling curriculum transformation. For Lesedi, it is ingrained in South Africa's transformation struggles to use violence. She said, 'In South Africa it is believed that to solve a problem, you need to be violent and that's not the case'. Elana also recognized this trait and said that 'unfortunately these are mostly the methods used in the marches' so she refrained from participating in the protests because she is 'not particularly in favor of violence or vandalism'. The forms of violence used by students were described by Nix as 'reactive and destructive' because of the vandalism. She drew specifically on how protesters were 'destroying labs, burning buildings and throwing stones'.

For Charmaine and Lisa, the violent approaches were counterproductive. Lisa drew on the way in which 'classes were disturbed and violently stopped and [on how] this inhibited other students from continuing with their academics'. She regarded this as 'totally unacceptable'. She explained,

Just because you have a problem with something, does not mean everyone must have a problem with it and stand together with you. This act is selfish, and unfair to me. Instead of giving students a chance at a better future, they took away other students' hope of a future. Burning and breaking down is not the only tactic to fight against something.

Charmaine's reasoning drew on how the use of violence portrays students negatively. She insisted,

I mean really, you are destroying stuff that will need to be replaced with money that you are demanding. This is so counterproductive. In actual fact, defeating your own purpose, your own cause through your own acts .... I think it gave [others] such a bad view [of us] as students. It says that we are not critical thinkers or that we do not factor in all the things that would come into play for the certain demands we have, that we cannot give arguments for the statements we make, that we would rather be seen as if we were hooligans who would vandalise and be violent to get our point across. That we do not see value in our 
own voices .... The primary school children and high school children look at you in your tertiary state and that is how you answer to problems or that is how you react to problems. You are not a problem solver and you are supposed to be at the highest level of education, tertiary education.

By questioning these violent actions, Charmaine described the far-reaching implications of students' violent acts as portraying all students in a bad light and she highlighted the example that this could communicate to younger generations. Ava was also critical of violence and she warned that it could be counterproductive to the decolonial project and in turn become 'just another form of colonisation and oppression'. Although scholars such as Fanon (1967) and Žižek (2012) draw on the use of violence as central to protest and change, these student participants experienced the violence used by student protestors as reactive, destructive, and disruptive. It can de deduced that these students are perhaps wary and cautious of curriculum transformation that is invested in a negative force of power ('potestas') (Le Grange 2019a: 40) that could, even if unintentionally, promote transformation that is hierarchical, transcendent, and colonising (violently demanding a way of knowing as the way). Instead, when curriculum change is invested in an active conceptual force it unlocks a productive and positive power (potentia) so that the cause of curriculum transformation is one that connects, affirms, and is joyous in bringing newness and the creation of things unforeseen. This notion of curriculum 'opens up multiple pathways for the becoming of pedagogical lives [with an] immanent potential to become other' (Le Grange 2019a: 40).

\subsection{Economic Repercussions and Curriculum Transformation}

Some students did not protest because of a heightened awareness of the economic repercussions this would incur and they regarded this as counterintuitive to achieving curriculum transformation. Lesedi reflected that 'South Africa was never ready for free tertiary education. It was not feasible looking at the current state of the country and the political fights in the country'. He went on to argue that students were destructive in the way they expressed their demands and this lead him to ask, 'If students burn buildings where education should take place, who will pay for the damages and also give you free education?' For Lisa, 'Free things are not valued' and that is why 


\section{Shan Simmonds}

education should not be free. Paballo shared a scenario; her institution used to issue learning materials but one of the outcomes of the student protests was her institution going paperless to cut costs. She shared that her losses were greater than her gains when she said,

We could not have free study guides any more. Instead we had to download them and that also took data when you needed to access the information from home. Even if you came to campus to get them for free it took you money to get here ... it took us back because the students ... didn't think about the repercussions of no fees and what that would then mean for the operations of higher education and education.

Revelations drew on another scenario. He was concerned that if student demands were met, lecturers might also incur financial losses, and this could be detrimental for 'the quality of education'. He explained, 'Lecturers were obviously going to earn less than they were getting, then they would relocate to another country, then the South African education system was going to suffer'. For Nix, none of this adds up because she is of the opinion that many of the students protesting took no responsibility for their demands through their learning. She elaborated that among the protesting students were those who 'failed and then complained when they did not receive NSFAS but they didn't take charge of their learning. They were playing, smoking, doing whatever they wanted to do and then they demand to go to school for free'.

The larger picture is missing for Charmaine. She argued that students did not think about the financial implications of what they were asking for. She felt strongly that there are 'critical arguments that they are not bringing to their demands or that they are not using to support their demands' and these include 'being critical about whose needs must be sacrificed in order for your cause or your demand to be met'. This includes deeper deliberations with questions such as: 'Who must suffer for fees to fall? Where must the money come from?' The experiences of these students provide nuanced perspectives of the various economic dimensions that came to the fore through the protest movements. On the surface a consequentialist view that focussed on the outcomes of actions, was expressed when student participants were inclined to weigh the likely social benefit against the costs incurred (see Cohen et al. 2011). But, given these experiences, a deeper discourse of discontent regarding physical 
destruction and a lack of accountability were repeatedly offered as counterproductive to transformation. This could signify the territorialisation of a reactive force which counterintuitively thwarts the active, affirmative potential of curriculum transformation to create newness that is affective, productive, and dynamic (Braidotti 2011).

\subsection{Allegorical Approaches for Curriculum Transformation}

Student participants spoke about the importance for higher education to take curriculum transformation seriously. Of the participants, 11 were explicit about their hopes of employing approaches other than those they witnessed. The approaches proposed included signing petitions (Elana; Nix; Othandwayo), campaigns (Nix), forums that generate debate (Ava; Lisa; Lesedi; Piet), conducting research (Don Voli; Lisa; Othandwayo) and dialogue (Charmaine; Lindie).

For Nix, petitions and campaigns need to be so provocative that they become propaganda. She explained,

We need to start actively advocating ... convincing people ... getting people on board ... making it our propaganda .... By not shouting. Speak, convince .... If you want to create awareness, be smart. Get charismatic students together, start informing by speaking to students of all cultural groups, speak to them in their language, and speak to them in ways that they can understand ... it's about actively advocating [by] building up and not breaking down.

For Charmaine and Lindie dialogue would prove to be a significant means for people to speak about the transformation they think is necessary. Dialogue through 'radio interviews and talking to each other' where people can really engage so that transformation discourses become 'a language and a topic amongst people' (Charmaine). This can happen, explains Charmaine, by setting a 'new precedent of how to approach problem solving and how to deal with problems. The culture of vandalizing must die out and we must begin to be critical thinkers who think about what we do and say'. Lindie added,

we need to open our hearts more and be willing to participate in dialogue and conversation that will lead to the strengthening and 
enhancing of our knowledge ... it is a process that cannot be rushed because it might cause fear and panic ... as we continue to be confronted with racial and religious instances on a daily basis.

These responses stress the need for student voices in bottom-up approaches in curriculum conversations. Alongside these, Lesedi drew on the importance of 'involving different stakeholders to deal with this issue'. For Piet this requires the involvement of the Department of Higher Education and Training and, for Revelations, that of 'our leaders', while Lisa said we cannot strive for curriculum transformation alone, 'we need to change the mindset of our nation'.

The approaches students hope for are communicative and dialectical in nature. Pinar's (2015) conception of allegory proves insightful here as we try to make sense of these students' aspirations. In its allegorical form, curriculum as currere accentuates its etymological root, to 'speak publicly in an assembly' and suggests that speaking allegorically is not merely an exchange of information. Its autobiographical, pedagogical, and communicative character invites 'reactivating the past so as to render the present' (Pinar 2012: 50). For Pinar (2012: 47) this necessitates complicated conversations as a specific kind of 'communication'. He avers that curriculum is an ongoing effort at communication with both oneself and with others that portends the social reconstruction of the public sphere. In this way, engagement with the self and the world is self-mobilizing and reconstructive through an allegory-of-the-present, a present that is historically conceived of so that through past experience we can begin to seek the meaning of the present and navigate ways to the future. This is significant since it ensures that there is 'no longer a flat line between what is no more and can never be, the present becomes a palimpsest' so that complicated conversations bring to life 'temporally structured, subjectively animated curriculum' (Pinar 2012: 47).

Students expressed their experiences of curriculum transformation in higher education through the events of the protest movements. These revealed the many agendas that they think underpin curriculum and that can influence its transformation. The themes (or agendas) present an analysis of students' experiences that should be read as interrelated and intersecting in their entanglement and that reveal the complex multilayered nature of curriculum transformation. What is aspired for in the wake of these experiences is the desire for allegorical approaches to curriculum transformation through lived curriculum as complicated conversation. 
In the next section I contemplate Pinar's (2012) notion of complicated conversation through the conception of lived curriculum that embraces subjectivity as attuned to the posthuman condition, in harmony with the natureculture continuum as non-linearity and embodied, embedded, and embrained in nomadic thought. Within the constructive tentionality of subjectivity and lived curriculum, curriculum as complicated conversations can be contemplated through nomadic thought.

\section{Lived Curriculum as a Complicated Conversation through Nomadic Thought}

Pinar's (2012: 44) currere as a verb infers an action, process, and experience aimed '[at studying] the relations between academic knowledge and life history in the interests of self-understanding and social reconstruction'. Advocating for a lived curriculum that is 'subjectively situated, socially engaged and historically attuned' (Pinar 2012: 48). Importantly, he offers currere as a means to 'reconceptualise curriculum from course objectives to complicated conversation' (Pinar 2012: 47). Currere, as a lived curriculum, is an ethical, political, always intellectual undertaking through complicated conversation in the name of educational experience. Its conversations are complicated by its multi-referenced interlocutors of self, other, and spatio-temporality and its ongoing nature, with no end to conversations and no anterior aims or objectives. As an autobiographical method through four moments (regressive, progressive, analytical and synthetical) (Pinar et al. 1995) it is not narcissistic. Rather 'it is conversation with oneself ... and with others threaded through academic knowledge, an ongoing project of self-understanding in which one becomes mobilised for engagement in the world' (Pinar 2012: 47). As an ongoing conversation, its complicatedness should not be rendered 'a pedagogical problem but an educational opportunity' (Pinar 2015: 111). As an erudite explanation of educational experience, Pinar's (2012) complicated conversation has without a doubt been revolutionary to (re)conceptualising curriculum studies.

As a starting point for (re)thinking lived curriculum as a complicated conversation, currere as an active conceptual force within ubuntu-currere proves insightful as Le Grange $(2019 b)$ points out. It accentuates that there is 'no a priori image of a pedagogical life, but multiple coursings for the becoming of a pedagogical life' (Le Grange 2019b: 221). Just as pathways for 


\section{Shan Simmonds}

becoming of a pedagogical life are not predetermined, they are unknown as is the ever-changing world in which they reside. Embracing an ontology of immanence, lived curriculum cannot be an interpersonal or intrapersonal experience alone. A material immanent plane 'that connects everything in the cosmos and from which all actualized forms unfold/become' could enable lived curriculum as an assemblage of human-human-nature in the posthuman condition (Le Grange 2019b: 223). But how might such an image of lived curriculum be fostered through complicated conversation? I suggest nomadic thought as one avenue since it is rooted in alternative visions of both the subject and the structure of knowledge. In other words, complicated conversations need to shift conceptions of the subject and knowledge if they are to be prolific in the posthuman era. Since much has been said in this article about the vision of the subject, I emphasise only some main arguments and then move on to discuss thinking and knowledge invested in nomadic thought.

Nomadic thought decenters the human so that subjectivity can devise 'new social, ethical and discursive schemes of subject formation to match the profound transformations we are undergoing' in the posthuman era (Braidotti 2013: 12). Complicated conversations must thus include a heightened awareness of who we are, our vital materialism that is neither organicist nor essentialist but pragmatic and immanent, since the 'practices and flows of becoming, [are] complex assemblages and heterogeneous relations' (p. 171). So as already mentioned, a vision of the subject as attuned to the posthuman condition embraces a nature - culture continuum of non-linearity and is embodied, embedded, and embrained through vital materialism. This vision demands different conceptualisations of ourselves in a process of defamiliarity. It requires critical and creative contemplation through complicated conversations that ask complex questions such as: Who are we? What are we in the process of becoming within the posthuman condition?

Also deeply etched in nomadic thought is unlocking the affirmative potential (as potentia) of alternative visions of the structure of thinking and knowledge. Non-linearity features here also since it proffers a rhizomatic style of thinking that 'allows for multiple connections and lines of interaction that necessarily connect the text to its many "outsides"' (Braidotti 2013: 165). What this could mean for complicated conversations is that it challenges 'the authority of a proper noun, a signature, a tradition, a canon or the prestige of an academic discipline' and resides, instead, in the 'transversal nature of the affects' that complicated conversations can engender through the relations they 
enable and sustain (Braidotti 2013: 165). Thinking and knowledge cannot be moulded into linearity, they must move outwards to encourage an 'affective opening-out', as 'webs of encounters with ideas, others [and] texts' (Braidotti 2013: 166). Complicated conversations can then be a space in which to engage with the intensity of these affective forces that shed light on what knowledge can do, what is has done, and how it has impacted on the self and others (human and non-human). Braidotti (2013) avers that central to this is the practice of defamiliarization. This is a process of disengagement from dominant normative visions of the subject and knowledge, evolving into a posthuman frame of reference in a relational connection to multiple others. Termed an 'anthropological exodus' by Braidotti (2013: 168), dis-identification involves the sense of loss and fear since it disrupts habits of thought and representation of 'century-old habits of anthropocentric thought and humanist arrogance'. The geo-centrism vital to nomadic thought must evoke radically imminent planetary dimensions as becoming-earth to break established patterns of thought. So, for complicated conversations to embody nomadic thought, humanist quintessential thought must be deterritorialised to allow for knowledge that fosters 'interdisciplinarity, transversality and boundarycrossings among a range of discourses' (Braidotti 2013: 169). This makes it possible for complicated conversations to take heed of what knowledge might look like or become in the posthuman condition by grappling with the complexity invested in questions such as: Whose and what knowledge is of most worth? What could/ should knowledge look like and become in the posthuman era?

\section{Conclusion}

Braidotti's (2013: 11) dream for universities resonates closely with my dream for a lived curriculum as complicated conversation. For her,

it is the dream of producing socially relevant knowledge that is attuned to basic principles of social justice, the respect for human decency and diversity, the rejection of false universalisms; the affirmation of positivity of difference; the principles of academic freedom, anti-racism, openness to others and conviviality.

When this dream is read juxtaposed with the outcry relating to the lived ex- 


\section{Shan Simmonds}

periences shared by students in this research study, their aspirations for complicated conversations speak vividly to university lecturers and to the curriculum. It encourages them, if not pleads with them, to take heed of students' aspirations and also see the necessity of these as invested in nomadic thought so that they can use their curriculum places and spaces to foster a pedagogical life in which the vision of the subject and knowledge must change. When complicated conversations, as the will to power, unlock the creative potential of what curriculum does or might do (Wallin 2010), then it can deterritorialise and counteract the reactive conceptual force of curriculum (potestas) through nomadic thought. Complicated conversations of this nature could be prolific in times when uncertainty is the only certainty, a time like the present when education remains infested and effected by the ills of manifestations resulting from, among others, environmental disasters (water depletion), rapid growth of technologies (fourth industrial revolution), and communicable diseases (coronavirus) and social unrest (calls for colonization of the curriculum). It is here, in lived curriculum as complicated conversation, that the transformative potential (as potentia) of curriculum lies. I offer this article as a place and space in which to embrace these constructive tensionalities, since in it I have considered nomadic thought as a departure point for (re)thinking lived curriculum as complicated conversation.

\section{References}

Aoki, T. 1993. Legitimating Lived Curriculum: Towards a Curricular Landscape of Multiplicity. Journal of Curriculum and Supervision 8, 3: 255-268.

Barnett, R. \& K. Coate. 2005. Engaging the Curriculum in Higher Education. Maidenhead: Society for Research into Higher Education \& Open University Press.

Braidotti, R. 2011. Nomadic Subjects: Embodiment and Sexual Difference in Contemporary Feminist Theory (2nd ed.). New York: Columbia University Press.

Braidotti, R. 2013. The Posthuman. Cambridge: Polity Press.

Chisholm, L. 2005. The Making of South Africa's National Curriculum

Statement. Journal of Curriculum Studies 37, 2: 193-208.

https://doi.org/10.1080/0022027042000236163 
Cohen, L., L. Manion, \& K. Morrison. 2011. Research Methods in Education (7th ed.). New York: Routledge.

Cross, M., R. Mungadi, \& S. Rouhani. 2002. From Policy to Practice: Curriculum Reform in South African Education. Comparative Education $38,2: 171-187$.

https://doi.org/10.1080/03050060220140566

Council on Higher Education. 2016. South African Higher Education Reviewed: Two Decades of Democracy. Pretoria: Council on Higher Education.

Department of Education. 1997. Education White Paper 3: A Programme for the Transformation of Higher Education. Government Gazette. Vol. 390, No. 18515. Pretoria: Government Printers.

Department of Education. 2008. The Report of the Ministerial Committee into Transformation in Higher Education (MCTHE). Pretoria: Department of Education.

Du Preez, P., S. Simmonds, \& A. Verhoef. 2016. Rethinking and Researching Transformation in Higher Education: A Meta-study of South African Trends. Transformation in Higher Education 1, 1: a2.

https://doi.org/10.4102/the.v1i1.2

Fanon F. 1967. Towards the African Revolution. H. Chevalier (trans.). New York, NY: Grove Press.

Haraway, D. 2006. When We Have Never Been Human, What Is to be Done? Theory, Culture \& Society 23, (7/8): 135-158.

https://doi.org/10.1177/0263276406069228

Jansen, J.D., 2002. Political Symbolism as Policy Craft: Explaining Nonreform in South African Education after Apartheid. Journal of Education Policy 17, 2: 199-215.

https://doi.org/10.1080/02680930110116534

Jansen, J.D. 2009. Knowledge in the Blood. United Kingdom: Stanford University Press.

Jansen, J.D. 2017. As by Fire: The End of the South African University. Cape Town: Tafelberg.

Lange, L. 2017. 20 Years of Higher Education Curriculum Policy in South Africa. Journal of Education 68: 31-57.

Le Grange, L. 2006. Curriculum: a Neglected Area in Discourses on Higher Education. South African Journal of Higher Education 20, 2: 189-194. https://doi.org/10.4314/sajhe.v20i2.25566 
Le Grange, L. 2019a. The Curriculum Case for Decolonization. In Jansen, J.D. (ed.). Decolonisation in Universities: The Politics of Knowledge. Johannesburg: Wits University Press. https://doi.org/10.18772/22019083351.7

Le Grange, L. 2019b.Currere's Active Force and the Concept of Ubuntu. In Hébert, C., N. Ng-A-Fook, A, Ibrahim, \& B. Smith (eds.). Internationalising Curriculum Studies: Histories, Environments and Critiques. New York: Palgrave Macmillan. https://doi.org/10.1007/9783-030-01352-3_13

Pinar, W. 1975. Curriculum Theorising: The Reconceptualists. Berkeley, CA: McCutchan.

Pinar, W. 2012. What is Curriculum Theory? (2nd ed.). New York: Routledge. https://doi.org/10.4324/9781410609793

Pinar, W 2015. Educational Experience as Lived: Knowledge, History, Alterity. The Selected works of William F. Pinar. New York: Routledge. https://doi.org/10.4324/9781315752594

Pinar, W., W. Reynolds, P. Slattery \& P. Taubman. 1995. Understanding Curriculum: An Introduction to the Study of Historical and Contemporary Curriculum Discourses. New York: Peter Lang.

Soudien, C. 2010a. Grasping the Nettle? South African Higher Education and its Transformative Imperatives. South African Journal of Higher Education 24, 5: 881-896.

Soudien, C. 2010b. Who Takes Responsibility for the 'Reitz Four'? Puzzling Our Way through Higher Education Transformation in South Africa. South African Journal of Science 106, 9/10: Article\#429. https://doi.org/10.4102/sajs.v106i9/10.429

Wallin, J.J. 2010. A Deleuzian Approach to Curriculum: Essays on a Pedagogical Life. New York: Palgrave Macmillan.

https://doi.org/10.1057/9780230115286

Žižek, S. 2012. The Year of Dreaming Dangerously. New York: Verso.

Shan Simmonds Associate Professor Department of Education and Human Rights in Diversity Research Unit North-West University

Potchefstroom shan.simmonds@nwu.ac.za 